\title{
We Know Nothing after Having Known Much A Documentary Re-Search Paper
}

\author{
Jamir Ahmed Choudhury \\ Re-search Scholar \& Assistant Professor of Philosophy, S. S. College, Hailakandi, Assam, Re-search Scholar on 'Solidarity Rights in Islam' \\ Under Assam University, Silchar, [AUS]
}

\begin{abstract}
We (mankind in general) are far from Manifest Truth (Class - II standard verifiable \& justifiable True Knowledge) due to Manifest Hypocrisy, Teleological Evidence Sorcery, Extreme Epistemic Persecution, and uninterrupted propagation of the Nexus of Self-evident Plagiarisms prevailing in the History of Formal Education \& Epistemology. This paper places 'justifiable appeal' for recognition and confirmation of the searched out Manifest Truths shared in the 'Kitaaba Wal-Hikmata' with reference to Infallible \& Unerring Mandates. This documentary paper with reference to 'Kitaaba Wal-Hikmata' or 'Manifested Nature and the Utility of One's Upright Logic', published by Partridge Publishing India, 2016, also places an Acid Test before International Scientific Soldiers (ISS) of Activism and Terrorism i.e. Manifest Hypocrites, Teleological Evidence Sorcerers, Extreme Epistemic Persecutors, and Propagators of the Nexus of Self-evident Plagiarisms.
\end{abstract}

Keywords: Universe, World, Earth, Sole Magnetism, Trinity, Four Cardinal Directions

Reference: - Searched out Manifest Truths shared as Solidified Solid Human Rights in the 'Kitaaba WalHikmata' or 'Manifested Nature and the Utility of One's Upright Logic', Vol. - 1 \& 2 of Jamir Ahmed Choudhury, Published by Partridge Publishing India, 2016

Teleology - Placement of Justifiable Appeal for Verification, Justification, and Upright Justness with the Searched out Manifest Truths shared as Solidified Solid Human Rights in the 'Kitaaba Wal-Hikmata' or 'Manifested Nature and the Utility of One's Upright Logic' Vol. - 1 \& 2 of Jamir Ahmed Choudhury, Published by Partridge Publishing India, 2016, and General Recognition \& Public Broadcasting of one of the Verifiable \& Justifiable Contradictory Sets [Set A or Set - B] with a view to get answers of 25 Class - II standard True Knowledge [Fill in the Blanks with True Alternatives in correspondence with Manifested Nautre]

Respected \& Honourable Sir / Madam,

With due import and honest submission before Honourable Chairs, Respective Authorities, Public Representatives, Govt. Officials, Possessors of Balanced Good Sense, and Mankind in general, I am going to place Infallible \& Unerring Mandates, Searched out Manifest Truths, Solidified Solid Human Rights with Justifiable Appeal as Duty for Duty's Sake with reference to I. Kant, Nishkama Karma with reference to Bhagvat Gita, Righteous Work [Tabligh] with reference to Complete Revelation, Moral \& Legitimate Responsibilities with reference to Teaching Profession, Solidarity Rights with reference to Rational Being living in Society, and the like, for Sanctity of Education with reference to History of Epistemology, Verifiable Truth of Facts with reference to Concealed Real Science, Justifiable Necessary Truth with reference to Four Revealed \& Established Standards [Criterions] of Truth as Philosophical Theories, Utilitarian Liberation with reference to J. S. Mill, Nirvana with reference to Buddha, Moksa with reference to Chaturtha Bharga Scheme of Purushartha of Bhagvat Gita, Survival of the Fittest with reference to Natural Environment, Sustainability with reference to
Manifested Nature, Social Justice with reference to Human Person of Peter Singer living in Society, Manifest Truth with reference to Injiil in correspondence with Tawraat, Uniform Principle \& Successive Relation with reference to Newton's Law of Gravitation \& Three Laws, Equal \& Opposite Manifested Signs of Natural Magnetism with reference to Einstein's Binary Pulsar [Niche], Greatest Happiness of the Greatest Number with reference to Moral Philosophy, Right Path towards Upright West facing each other in resemblance with Upright Nature of Ibrahim (ass) and in correspondence with Equal \& Opposite Manifested Signs of Sole Magnetism $\&$ Crucified Sign with reference to Complete Coded Shared Tautologies [Universal Major Premises], Appointed Day of observing Idd Uniformly on the Equal \& Opposite Morning i.e. same day in resemblance with the alteration of Day \& Night and in correspondence with arising \& appearing of Equal \& Opposite New Moons for the Equal \& Opposite Seashores, Justness in resemblance with the Infallible \& Unerring Mandates of the Revealed Trinity [Sirius Binary System] and Established Bond of First Generation - Second Generation - Third Generation Rights of Human Persons living in Societies called Solidified Solid Human Rights, Survival of the Truest with reference to individual Faith \& Belief, and the like, following Three Core Teachings of Dharma [Upright Nature / Righteousness] as shared in Bhagvat Gita - 'Do what is Right', 'Choose what is Good', and 'Sticking to what is Truth' as well as Three Logical Methods, namely, Dictum De Omni Et Nullo, Cartesian Method, and Cogito Ergo Sum.

\section{That Sir / Madam,}

It is not only perplexing but also surprising \& shameful fact that though we are human persons by creation and social beings by nature living in societies, yet we [almost all save International Historical Killers of Faith \& Belief of Mankind in general on Scientific Certainty \& Formal Education i.e. International Scientific Soldiers (ISS) of Activism and Terrorism] are far from the self-evident concepts of Diamond Operator [Intrinsically Luminous Four-Figured Fixed Star], Trinity [Sirius Binary System], Galaxy of Stars [West Horizon / Jupiter], Star System, Upright Rectangular 


\section{International Journal of Science and Research (IJSR) \\ ISSN (Online): 2319-7064}

Index Copernicus Value (2015): 78.96 | Impact Factor (2015): 6.391

Universe [in resemblance with End of Proof of Concealed Real Science \& in correspondence with the appointed Kaba on the Right side of the Mount Tuur in the Upright West Region of Arabian Peninsula], Helium - 4 [two Horizons \& two Hemispheres], Immovable Hexagonal World [Asterisk of Concealed Real Science], Two Zones [East Zone or Lower Seashore and West Zone or Upper Seashore], Six Regions [in resemblance with the creation of the world in six days / six brothers of Pandavas], two East \& two West, Manifested North [E-Point / North Pole / Northern Hemisphere / Haiyalas-Swalaah] \& Manifested South [TPoint / South Pole / Southern Hemisphere / HaiyalalFalaah], Appearing Pentagonal Earth in correspondence with 9/11 Pentagon [Star Operator / Spiders' Net / House / Kamala-Lebu / Titanic / Nuuh's Ark / Five Brothers of Pancha Pandavas / Pentagonal Tent as Referred by Prophet Muhammad (sas)], Three Ascending Stairs [Super Script ${ }^{1} 23$ $/ 1 / 2+3 / 4+1 / 4 /$ Tiin - Zaytuun - Tuur / Three Stairs in a Mimbar], North-East Region of North America \& South East Region of South America in the Ground Stair of the East Zone [Lower Seashore], Straight Middle-East Region of Bermuda Triangle [Eartha 3D / Hole in the journey boat of Muussa (ass) / Hollow in the Hand (Pentagon)] on the Cross in the East Zone, South-West Region of Europe as well as North-West Region which comprises Asia, Africa, and Australia of the Middle Stair in the West Zone [Upper Seashore], Upright West Region of Arabian Peninsula or Topmost Stair [Uppermost Land] in the West Zone, Equal \& Opposite Law of Newton [Ongoing 3D command / 3D Arrow of Scientific Certainty or Three Minutes after Big Bang], Equal \& Opposite Semi-anticlockwise [4/8 or $1 / 2$ ] and Semi-clockwise [3/4 $+1 / 4]$ stages of journey of the Manifested Sign of Sole Magnetism from North to South for the East Zone \& South to North for the West Zone i.e. twice rising and twice setting of the so-called Sun [Bullet / Sister Planet Venus / Einstein's Electromagnetic Wave / Converted Snake of Muussa's Staff / Maryam supplied with Sustenance / Movements of the Snake appearing in the neck of Shivji] with a view to cause the alteration of Day \& Night for the Equal \& Opposite Seashore, Broken Bar, Veto or Barrier [Electron Cloud / Screen / Lakshman Rekha / Veil] between Equal \& Opposite Manifested Sign of Sole Magnetism [Ram Rajya and Lankeswar Ravana / West Zone and East Zone], Appointed Day of observing Idd on the basis of the arising \& appearing of New Moons [Uranus \& Neptune / Muzzammil \& Muddassir] for the Equal \& Opposite West Zone \& East Zone as Signs of Successive Relation, Four Blessed Springs for Straight Uses [Four Galilean Moons / Four Pillars (Imams) of the Appearing Pentagon], Four Components of an Atom [Electron, Proton, Neutrino, and Neutron], Seven Canopies [Windows] in the West Horizon and similar Number in the East Horizon [Sapta Akash o Sapta Jomin], Twelve Octagonal Matter Particles [so-called sun spots / Black Spots] in resemblance with Equal \& Opposite Mercuric Year, difference between Triangular Axis and Elliptical Orbit [Arithmetic Progression and Geometric Succession], and the like. In brief, we know nothing after having known much.

Revealed Truth - The so-called sun and commonly perceived white moon [Niche / Binary Pulsar of Einstein] neither enter / arise \& rise / appear from the East nor end / set \& disappear in the West [Ref. Sura - Nuurun Aala Nuur, $\mathrm{A} / \mathrm{V}-35]$

Concealment of Manifest Truths and Projection of Manmade Falsehoods in the name of Scientific Certainties within the domain of Formal Education are the Vera Causa of Subjective Self-contradictions and Objective Paradoxes. These activities resemble with the nature \& function of Shaytan / Devil [Revealed Truth] / Maya [Advaita Vedanta of Sankara \& Upanisad]. Projection of Manmade Magnetism, Copernican Universal Mal-observation, Kepler's Elliptical Axis etc. in the name of Scientific Certainties and propagation of invented lies \& introduced falsehoods as Manifest Truths through the uncountable penpaper-pencil works \& mechanisms like the advertisements of man-made products are the concrete examples of Devils' Handworks in correspondence with the function of Maya of Advaita Vedanta. Due to invented lies and introduced falsehoods in the domain of Scientific Certainty as well as propagation of the Nexus of Self-evident Plagiarisms in the name of Research Works within the domain of Formal Education, we are far from Irreversible Manifest Truths. From the ongoing Epistemology concerning Manifested Nature [Manifest Truth], it is being appeared that the sole purpose of education is to acquire / share invented lies and introduced falsehoods as Manifest Truths. Propagation of the Nexus of Self-evident Plagiarisms i.e. Research Works on the basis of Reference List of Evidence Sorcerers and Epistemic Persecutors ['Rucksack of According to' only] as well as Justice done in the name of Universal Concern, Unanimous Agreement, Global Rights, Man-made Contrary Formalities and Contradictory Mandates with respect to Manifest Truth [Manifested Nature] \& Solidarity Rights [Ref. Letter No. 17016/51/2016-SCO-VI Dated $27^{\text {th }}$ October, 2016, Department of Social Justice and Empowerment Ministry, Govt. of India] are the real causes of leading without Broken Bar, human persons [regardless of Class, Caste, Ism, Nation, Tribe etc.] of Peter Singer living in societies towards Arguing in a Circle, Petitio Principii, Post Hoc Ergo Propter Hoc Statistics, Extreme Epistemic Persecution [Veil of Ignorance], Uninterrupted Killing of Faith \& Belief of Mankind in general on Formal Education [Depth of Darkness], Existential Fallacy, Plurality of Causes, Fallacy of Non-observation, Fallacy of Malobservation, Characteristic Imperfection, Practical Imperfection, Ambiguity, Absurdity, Illicit Fallacy etc. Subsequently, Shaytan / Devil and his agents [members of ISS] are leading human persons of Peter Signer from Appointed Light [Manifest Truth / Innate Idea of Rene Descartes] towards Depth of Darkness [Universal Concern \& Unanimous Agreement / Tabula Rasa of John Locke] projecting Black Clothe over Privative Eyes of Maryam [Veil of Ignorance of John Rawls / Unda-Kanuun / Global Rights \& Manmade Mandates with a view to conceal Manifest Truths] so that invented lies \& introduced falsehoods such as Copernican Circular Rotation \& Revolution System and Kepler's Elliptical Axis can be placed in equal \& opposite side of Newton's Stand less Balance Diagram [Unicode (hex) - 2696]. So, historically, we are far from true concepts of Manifested Nature [Manifest Truth or Injiil in correspondence with Tawraat] and Manifested Magnetic Directions grounded on the Appointed Light as the means of Sustenance as well as 


\section{International Journal of Science and Research (IJSR) \\ ISSN (Online): 2319-7064}

Index Copernicus Value (2015): 78.96 | Impact Factor (2015): 6.391

Equal \& Opposite Manifested Sign of Sole Magnetism within the Non-luminous Moon [Black Square] of East Horizon [Saturn].

As a human person living in society, as a Govt. appointed Lecturer of Justifiable Necessary Truth called Philosophy in a College, and as a research scholar under one of the Central Universities of India on Solidarity Rights, I have searched out several Manifest Truths and Solidified Solidarity Rights which are being concealed historically from mankind in general as well as from the domain of Epistemology. As the searched out Manifest Truths are both contrary as well as contradictory to invented lies and introduced falsehoods prevailing in the History of Epistemology, so, I had failed to place the searched out Manifest Truths formally in their right places following contrary formalities and contradictory guidelines imposed within the domain of re-search work. Failing to place those searched out manifest truths in their legitimate places, I had to compile the searched out findings following Dictum De Omni Et Nullo of Aristotle, Cartesian Method of Rene Descartes, and Deductive Method i.e. Logically in the name of 'Kitaaba Wal-Hikmata' or 'Manifested Nature and the Utility of One's Upright Logic' and got the compiled works self-published by Partridge Publishing India, 2016 in two Volumes [Pages $740+840$ ].

Each searched out Manifest Truth shared in the 'Kitaaba Wal-Hikmata' is verifiable as well as justifiable on the basis of Four Revealed and Established Criterions [Standards] of Truth in resemblance with Universal Major Premises [Coded Shared Tautologies] and in correspondence with Manifested Nature. Four Revealed \& Established Criterions [Standards] of Truth are - Coherence Truth [Tawraat / Equal \& Opposite Law], Correspondence Truth [Injiil / Manifested Nature / Observation of Particular Instances], Pragmatic Truth [Zabuur / Workability / Verifiable Truth of Facts], and Selfevident Truth [Furqaan / individual Recognition \& Confirmation of Manifest Truth / Justifiable Necessary Truth / Cogito Ergo Sum]. Each searched out Manifest Truth is a verifiable truth of fact [Real Science / Certain Knowledge] and justifiable necessary truth [True Philosophy / Valid Knowledge] which has been shared in the 'Kitaaba Wal-Hikmata' as Duty for Duty's Sake for verification, justification, rejection, confirmation, and general recognition. It is self-evident that there no finite being or epistemic person or sceptic who has the capability to contradict or to reject an Irreversible Manifest Truth. Manifest Truth in correspondence with Equal \& Opposite Law of Revelation is beyond Manmade Mandates, as Manmade Laws, Clauses, Articles, and Chapters have no Sovereignty over Manifested Nature.

'Kitaaba Wal-Hikmata' or 'Manifested Nature and the Utility of One's Upright Logic' not only explores vera causa of Subjective Self-contradictions and Objective Paradoxes with experimentum crusis and crucial instances i.e. the Trinity of Manifest Hypocrisy - Teleological Evidence Sorcery - Extreme Epistemic Persecution as well as propagation of the Nexus of Self-evident Plagiarisms, but also shares first time in the History of Epistemology several searched out Manifest Truths which are being concealed from mankind in general. For this reason, it is necessary to verify, justify, reject, recognise, confirm, generalise, and broadcast those searched out Manifest Truths by the Honourable Chairs, Respective Authorities, Scientific Research Institutions, NAAC, UGC, Philosophers, Scientists, Epistemic Persons, Religious Scholars, Researchers, Possessors of Balanced Good Sense, Publication \& Broadcasting Media, and Mankind in general for 'Sanctity of Education', 'Utilitarian Liberation', 'Survival of the Truest' etc. In this regard, 'Kitaaba WalHikmata' or 'Manifested Nature and the Utility of One's Upright Logic' honestly and sincerely places 'Justifiable Appeal' before all to make an attempt with a view to erase invented lies \& introduced falsehoods from the domain of Epistemology as well as to recognise, confirm, and introduce Manifest Truths within the domain of Formal Education. Further, 'Kitaaba Wal-Hikmata' also consciously invites those epistemic persons and sceptics of Irreversible Manifest Truths who have the capability to argue either in favour of invented lies and introduced falsehoods prevailing in the history of Epistemology in the name of Scientific Certainties and Formal Education or against searched out Manifest Truths shared as Solidified Solid Human Rights with an alternative option i.e. reject or recognise searched out Manifest Truth. This 'Justifiable Appeal' will be published in the Third Volume of 'Kitaaba Wal-Hikmata' or 'Manifested Nature and the Utility of One's Upright Logic' as 'General Appeal' as a Duty for Duty's Sake for the 'Sanctity of Education' as well as 'Greatest Happiness of the Greatest Number'.

\begin{tabular}{|c|c|}
\hline \multicolumn{2}{|c|}{$\begin{array}{c}\text { Revealed Truth - Persecution is worse than killing } \\
\text { REJECT OR RECOGNISE SEARCHED OUT MANIFEST TRUTH }\end{array}$} \\
\hline \multicolumn{2}{|c|}{ Two Contrary as well as Contradictory Sets regarding Manifest Truth \& Manifested Nature } \\
\hline SET - A & SET - B \\
\hline $\begin{array}{l}\text { Invented Lies and Introduced Falsehoods } \\
\text { Or }\end{array}$ & $\begin{array}{l}\text { Manifest Truths / Concealed Real Science and Highlights of the } \\
\text { Searched out Significant Findings shared in the 'Kitaaba Wal- }\end{array}$ \\
\hline Historically Prevailing Epistemology projected by the & Hikmata' or 'Manifested Nature and the Utility of One's Upright \\
\hline $\begin{array}{l}\text { Persecutors [members of ISS] of Faith \& Belief on Manifest } \\
\text { Truth }\end{array}$ & Logic' of Jamir Ahmed Choudhury \\
\hline $\begin{array}{l}\text { No self-evident definition of the Universe is being found in the } \\
\text { uncountable works of the epistemic persons. Universe means } \\
\text { 'All existing things'. Ref. Dictionary }\end{array}$ & $\begin{array}{l}\text { Universe [Alamin] is a four-figured intrinsically luminous star called } \\
\text { Diamond Operator [Sirius or Siira or Shining Star]. Ref. from } \\
\text { Concealed Real Science - Unicode (hex) }-22 \mathrm{C} 4\end{array}$ \\
\hline $\begin{array}{l}\text { Universe is a running and moving Global Trinity as well as } \\
\text { Quaternary. }\end{array}$ & Universe is a Quadrilateral Fixed Star. Ref. Symbol (hex) - 003F \\
\hline Moon is the Earth's only permanent Natural Satellite. & $\begin{array}{l}\text { Diamond Operator [Siira / Sirius] is the Earth's only permanent } \\
\text { Natural Satellite. }\end{array}$ \\
\hline
\end{tabular}




\section{International Journal of Science and Research (IJSR) \\ ISSN (Online): 2319-7064}

Index Copernicus Value (2015): 78.96 | Impact Factor (2015): 6.391

Universe is a Solar System i.e. Circular Rotation \& Revolution

Universe is a Planetary System.

Manifested Universe is a Mechanism of Nine Planets i.e. Planetary System or Astral System or Cosmological System or Astrophysical System or Stellar System.

Manifested World resembles with Running \& Moving Globe or Wheel of Dharma [Unicode (hex) - 2638]

Manifested World is a running and moving Global Cosmos or Spherical Globe or Restless Wheel of Dharma in resemblance with Petitio Principii.

Appearing Earth is also synonymous with Running Globe, Moving World, and Running \& Moving Universe. There is no difference between Global Universe, Spherical World, and Circular Earth. So, it is obvious that there is internal harmony among / between Global Trinity. This internal harmony is called Globalisation i.e. Semi-anticlockwise \& Semi-clockwise full circle or Common Run or Universal Concern or Unanimous Agreement or Revolutionised Universal Mal-observation.

Though there are seashores, land, hills etc. in the Manifested World and the Appearing Earth within the Universe, yet there is no ascending or descending stairway either in the Moving World or in the Running Earth or in the Running \& Moving Universe.

There are two hemispheres in the Running \& Moving Global Trinity as well as Quaternary. The upper half of the moving world is called Northern Hemisphere in resemblance with projected North America and the lower half of the moving earth is called Southern Hemisphere in resemblance with projected South America. There is neither East Horizon \& West Horizon, nor East Zone \& West Zone in the running \& moving Universe, World, and Earth

There are four cardinal directions, namely, East, West, North, and South. Facing towards entering / rising sun, the left side is North and the right side is South for the Equal \& Opposite East Zone and West Zone. So, there are two North i.e. Upward Direction in resemblance with projected Northern Hemisphere and Left Side facing towards entering / rising sun. Similarly, there are two South.

There are seven continents in the world. or Common Run.

There are seven continents in the Earth.

Universe is a Trinity or Sirius Binary System [Samawati wal Arz West \& East Horizons].

Universe is a Star System.

Manifested Universe resembles with an upright man and 'End of Proof' [Unicode (hex) $-220 \mathrm{E}$ ] as well as it corresponds with the appointed Kaba in the Upright West Region within the Black Square of East Horizon

Manifested World is a Hexagon created in six days or Asterisk [Unicode (hex) - 002A] or Star of David [Unicode (hex) - 2721]

Equal \& Opposite ongoing Command or 3D Arrow of Scientific Certainty or Straight Middle-East Region of Eartha 3D or Projected Planet Mars is the Peg or Caduceus [Unicode (hex) - 2624 \& Symbol (hex) 0095] of the Immovable Hexagonal World.

Due to Straight Middle-East Region of Bermuda Triangle of Titanic [Caduceus / Planet Mars / Black Hole], Manifested Hexagonal World is appearing as a Pentagon in correspondence with 9/11 Pentagon in the East Zone. So, the appearing Earth is a Pentagon in resemblance with Spiders' Net [Symbol (hex) - 0022], House [Unicode (hex) - 2302], Star Operator or Pentagonal Star in correspondence with the Star of the Star TV [Unicode (hex) 269D, 29C6, 272C, 2302, 2730, 272F]

Appearing Earth has three ascending Stairs [Unicode (hex) - 26B6] namely, Superscript ${ }^{1}$ [ASCII (hex) - 0089] or Tiin or Ground Stair, Superscript $^{2}$ [ASCII (hex) 00B2] or Zaytuun or Middle Stair, and Superscript $^{3}$ [ASCII (hex) - 00B3] or Tuur or Topmost Stair.

Helium - 4 represents two Horizons and two Hemispheres. From the point of view of Equal \& Opposite Revelation, the upper part of the Trinity or Sirius Binary System in resemblance with the upper dot of a division sign is called West Horizon [Projected Planet Jupiter Samwat] and the lower part in resemblance with the lower dot of the division sign is called East Horizon [Projected Planet Saturn / Arz] [Unicode (hex) - 23DB]. There are seven canopies or windows in the West Horizon and similar number in the East Horizon. The Revealed Left is called Northern Hemisphere and the Revealed Right is called Southern Hemisphere [Unicode (hex) - 2385].

The East Horizon Guarded by the Four Basic Forces is called Black Square or what Conspiracy Science calls Non-Luminous Moon [Saturn within Ring]. The East Horizon has been divided into two Zones. The Upper Seashore is called West Zone and the Lower Seashore is called East Zone [Symbol (hex) - 0031]. So, there are two West [West Horizon \& West Zone] and two East [East Horizon \& East Zone]. [Ref. A / V - 17 of S - A-Rahman]

There are four cardinal directions and six Manifested Directions in resemblance with six Regions of the Manifested Hexagonal World.

The Lower Seashore [East Zone] comprises North-East Region of North America, South-East Region of South America, and Straight Middle-East Region of Eartha 3D [Bermuda Triangle of Titanic] on the cross.

The Upper Seashore [West Zone] comprises South-West Region of Europe, North-West Region of Asia, Africa, and Australia as well as Upright West Region of Arabian Peninsula.

Asia is a North-Western Continent.

Asia is an Eastern Continent.

There are three ascending stairways in the Appearing Pentagonal Earth. As the peg of the immovable world, Straight Middle-East Region of Eartha 3D [Bermuda Triangle of Titanic / Planet Mars / Black Hole] on the cross is not found in appearance. The remaining two Regions of the East Zone i.e. North-East Region of North America and South-East Region of South America represent Ground Stair or Superscript ${ }^{1}$ [Tiin] of the appearing Pentagonal Earth in resemblance with converted Red and Green shades of Windows'7 Ultimate.

South-West Region of Europe as well as North-West Region which comprises Asia, Africa, and Australia represent Middle Stair or Superscript ${ }^{2}$ [Zaytuun] of the appearing Pentagonal Earth in resemblance with converted Yellow and Blue shades of Windows'7 Ultimate. The Upright West Region of Arabian Peninsula represents Topmost [Uppermost] Stair or Superscript ${ }^{3}$ [Tuur] of the appearing Pentagonal Earth in resemblance with white cloud at the centre of 


\section{International Journal of Science and Research (IJSR) ISSN (Online): 2319-7064}

\begin{tabular}{l}
\hline Arabian Peninsula is in the Straight Middle-East Region of \\
Eartha 3D [Hole in the journey boat of Muussa (ass) or Hollow \\
in the Hand or Black Hole]. Disbelievers [Kaffirs] are those \\
who have faith on four independent revelations \& 6310 critical \\
remarks of IFTA on Quran and two kinds of magnetism of the \\
Conspiracy Scientists of NASA. They have rejected Faith on \\
Principle of the Uniformity of Nature and belief on Equal \& \\
Opposite Manifested Sign of Sole Magnetism from North to \\
South and South to North. Moreover, they believe that Middle- \\
East is the Equal \& Opposite Region of the appointed Kaba and \\
the Black Hole [Bermuda Triangle of Titanic]. So, they are \\
performing Salat [Namaz] towards the appointed Kaba which \\
has been projected in the Straight Middle-East Region of Eartha \\
3D by the ISS of Activism and Terrorism or Killers of Faith \& \\
Belief of Mankind in general on Manifest Truth.
\end{tabular}

The so-called Sun [Electromagnetic Wave of Einstein / Bullet / Manifested Sign of Natural Magnetism] rises once from the East [Gravitational Field] and sets once in the West [Strong Field] to cause the alteration of Day \& Night for the Equal \& Opposite East Zone and West Zone. These are called Post Hoc Ergo Propter Hoc Statistics which are being taught historically as Scientific Certainties and Primary Formal Education with a view to create subjective self-contradictions and objective paradoxes in the psyche of fresh generation and to lead mankind towards depth of darkness [projected straight Middle-East Region].

There are Four Basic Forces [Four Imams or Four Blessed Springs for Straight Uses]. The so-called Sun [Bullet - ASCII (hex) - 0095] is the Manifested Sign of Einstein's Electromagnetic Wave. As the entering direction of the socalled Sun [Bullet] for the East Zone has been projected as East, so, East Direction represents Natural Magnetic Direction. Similarly, the rising direction of the so-called Sun [Bullet] for the West Zone is also called East, so, East Direction represents two Natural Magnetic Directions. This implies that there are two Northern Hemispheres [Magnetic Fields].

Further, the equal \& opposite setting \& ending directions of Einstein's Electromagnetic Wave [so-called Sun or Bullet] has been projected as West. So, West represents both Natural Magnetic Field and Natural Weak Field. There is no Strong Field. There is a reference of Gravitational Field in Newton's Law of Gravitation, but it has no fixed direction. Consequently, when an apple falls from the tallest tree of Newton, it fails to search out Gravitational Field in the running and moving Global Land. So, it begins to rotate and revolve round the Electromagnetic Wave [so-called Sun / Bullet]. On the basis of this sound hypothesis, it is being proved that the Manifested Hexagonal World and Appearing Pentagonal Earth move round the Appointed Light [Electromagnetic Wave / so-called Sun or Bullet].

There are two kinds of Magnetism. One is Natural Magnetism and the other is the introduced falsehood in resemblance with introduced Dead Calf or Idol of Firawn. This introduced falsehood in the name of Scientific Certainty within the domain of Formal Education is called Manmade Magnetism of ISS. Disbelievers [Kaffirs] are those who believe in two kinds of Magnetism of the Persecutors i.e. two realities of the ISS of Activism and Terrorism. So, they are none but Idolaters.

The direction from which the Electromagnetic Wave [so-called Sun / Bullet / Manifested Sign of Sole Magnetism] enters for the Ground Stair of North America and South America of the

Windows'7 Ultimate.

Kaba has been appointed on the right side of the Mount Tuur in the Upright West Region of the Manifested Hexagonal World, Topmost Stair out of Three Ascending Stairs, and Uppermost land of the appearing Pentagonal Earth [Symbol (hex) - 0041] called Arabian Peninsula. So, it is my Solidified Solid Human Rights to perform Salat [Namaz] on the basis of the appointed Kaba in the Topmost Stair or Upright West Region of the Manifested Hexagonal World and Uppermost Land of the appearing Pentagonal Earth. Projection of Equal \& Opposite Bermuda Triangle on the cross [Black Hole] and the appointed Kaba in the Straight Middle-East Region of the Global Trinity is nothing but persecution of Faith and Belief not only of Muslims but also of Mankind in general. In this regard, 'Kitaaba Wal-Hikmata' has already announced Greatest War [Jihade-Akbar] against the Trinity of Manifest Hypocrites - Teleological Evidence Sorcerers - Extreme Epistemic Persecutors, propagators of the Nexus of Self-evident Plagiarisms, and ISS of Activism \& Terrorism.

The so-called Sun [Electromagnetic Wave of Einstein / Bullet Manifested Sign of Natural Magnetism] rises twice and sets twice from North [Magnetic Field] to South [Weak Field] and turning back from South [Weak Field] to the end point i.e. North [Magnetic Field]. These are the Manifested Statistics of the alteration of Day \& Night for the Equal \& Opposite Lower Seashore [East Zone] and Upper Seashore [West Zone]. 'Kitaaba Wal-Hikmata' of Jamir Ahmed Choudhury, published by Partridge Publishing, 2016, is the First Work in the History of Epistemology which shares clearly and distinctly these Irreversible Manifest Truths.

There are four Cardinal Directions in resemblance with Four Basic Forces [Tawraat] and in correspondence with Crucified Sign [Injiil]. East represents Gravitational Force. Newton's apple falls from the tallest tree towards East i.e. Ground or Gravitational Field [Land / Arz]. West represents Strong Force. Rain comes from the West [Sky Samawat]. North represents Magnetic Force. Einstein's Electromagnetic Wave [so-called Sun / Bullet / Appointed Light within the Black Square of East Horizon] is the Manifested Sign of Sole Magnetism [Natural Magnetism]. So, the so-called Sun [Bullet] enters as day light for the East Zone of North America and South America from Magnetic Field i.e. North and sets in South [Weak Field]. The so-called setting Sun [Bullet] turns back from there and rises from South [Weak Field] for the West Zone of Europe, Arabian Peninsula, Asia, Africa, and Australia. This is called Equal \& Opposite stages of journey of the Manifested Sign of Sole Magnetism. These Equal \& Opposite stages of journey of the Manifested Sign of Natural Magnetism i.e. twice rising \& twice setting of the so-called sun cause the alteration of Day \& Night for the Equal \& Opposite Lower Seashore and Upper Seashore. Hypocrites \& ISS such as Copernicus and Kepler, introduced falsehoods such as Manmade Magnetism and Manmade Mandates have no Sovereignty over stages of journey of the Manifested Sign of Natural Magnetism [Injiil] in correspondence with Equal \& Opposite Law] [Ref. Equal \& Opposite Tree in the Red Colour Shade of Windows'7 Ultimate, Anticlockwise Top Semi-Circle Arrow i.e. from North to South (Unicode hex - 2186) and Clockwise Top Semi-circle Arrow i.e. from South to North (Unicode hex 2182), A / No. - 17 of Sura - As-haabal-Kahf]

The Principle of the Uniformity of Nature Categorically implies that there is only one kind of Magnetism. This sole Magnetism from North to South and turning back from South to North is called Natural Magnetism.

It is nothing but acquired epistemology which causes people of the book and subsequently mankind in general to reject faith on Equal \& Opposite Manifested Sign of Sole Magnetism from North to South \& South to North, and to choose two realities i.e. two kinds of Magnetism introduced by ISS.

The direction from which Electromagnetic Wave [so-called Sun Bullet] enters for the Ground Stair of North America and South America of the East Zone is the Revealed Left and Manifested Right 


\section{International Journal of Science and Research (IJSR) ISSN (Online): 2319-7064 \\ Index Copernicus Value (2015): 78.96 | Impact Factor (2015): 6.391}

East Zone is called East [Gravitational Field]. The direction towards which the so-called sun [Bullet / Manifested Sign of Natural Magnetism] sets for the East Zone is called West [Strong Field].

The direction from which the Electromagnetic Wave [so-called Sun / Bullet / Manifested Sign of Sole Magnetism] rises for the Middle Stair of Europe, Asia, Africa, and Australia as well as Topmost Stair of Arabian Peninsula of the West Zone is also called East [Gravitational Field]. The direction towards which the so-called sun [Bullet / Manifested Sign of Natural Magnetism] ends for the West Zone is also called West [Strong Field].

Due to Copernican Hypothesis, Kepler's Elliptical Axis, introduced Manmade Magnetism, Universal Concern, Unanimous Agreement, Global Rights, International Harmony, and the like the Electromagnetic Wave of Einstein [so-called Sun or Bullet or Appointed Light as the Means of Sustenance] rises once from the East i.e. Gravitational Field and sets once in the West i.e. Strong Field to cause the alteration of Day \& Night for the Equal \& Opposite East Zone and West Zone.

Introduced Dead Calf [Idol] of Firawn as mentioned in the 'Kitaab with Truth' is the introduced Manmade Magnetism of Conspiracy Science. This Manmade Magnetism represents Manifested North Pole and Manifested South Pole of the epistemic persons as well as their Manifested Nature; while equal \& opposite stages of journey of the manifested sign of Natural Magnetism from North to South \& South to North represents Mechanical Nature. Circular Rotation \& Revolution of $(C) \& \mathbb{B}$ is the Common Run [Golden Mean] between Manifested Nature of the ISS of Activism and Terrorism as well as Mechanical Nature in resemblance with Rotation \& Revolution System of Copernicus. This is called Globalisation.

Introduced Manmade Magnetism is the Standard [Criterion] of determining Revealed Left and Manifested Right i.e. North [Haiyalas-Swalaah / Aphelion] as well as Revealed Right and Manifested Left i.e. South [Haiyalal-Falaah / Perihelion].

Idolaters [followers of introduced idol of Firawn or introduced manmade magnetism of Conspiracy Science] of the Middle Stair of Europe, Asia, Africa, and Australia are performing Salat [Namaz] towards Straight Middle-East Region of Bermuda Triangle [Black Hole] on the cross in resemblance with ending direction of the Manifested Sign of Natural Magnetism for the West Zone i.e. North or Haiyalas-Swalaah or Aphelion.

Idolaters [followers of introduced idol of Firawn or introduced manmade magnetism of Conspiracy Science] of the Ground Stair of North America and South America are performing Salat [Namaz] towards Straight Middle-East Region of Eartha 3D [Black Hole] on the cross in resemblance with the setting direction of the Manifested Sign of Natural Magnetism for the East Zone i.e. South or Haiyalal-Falaah or Perihelion.

The Moon is Non-luminous, yet it has eclipse. The so-called Scientists often visit commonly perceived white moon. However, there are four Galilean Moons and 69 Moons of Scientific Certainty. So, the questions are - Out of four Galilean Moons, which one is the Nil Arm Strong's visited Moon? In which Moon [out of 69 Moons of Scientific Certainty] the so-called Scientists often visit?

Kepler's Elliptical Axis is the binary $\sim$ sth between Arithmetical Progression [Periodic Motion] of commonly perceived white moon and Geometric Progression [Rapid Succession] of the socalled Sun [Bullet] as the Manifested Sign of Natural Magnetism. This $\sim$ sth is called Solar System of Conspiracy Science and Dog's Paw with reference to 'Kitaab with Truth'.

It is being projected that there is only one Moon which rises from the projected Equal \& Opposite Middle-East Region of the Appointed Kaba and Bermuda Triangle of Titanic. So, i.e. North [Haiyalas-Swalaah / Aphelion]. The direction towards which the Manifested Sign of Natural Magnetism [so-called Sun] sets for the East Zone is Revealed Right and Manifested Left i.e. South [Haiyalal-Falaah / Perihelion].

The direction from which Electromagnetic Wave [so-called Sun / Bullet] turns back and rises for the Middle Stair of Europe, Asia, Africa, and Australia as well as Topmost Stair of Arabian Peninsula of the West Zone is the Revealed Right and Manifested Left i.e. South [Haiyalal-Falaah / Perihelion]. The direction towards which the Manifested Sign of Natural Magnetism [so-called Sun] ends for the West Zone is Revealed Left and Manifested Right i.e. North [Haiyalas-Swalaah / Aphelion].

The so-called Sun [Bullet] enters from North and covers semianticlockwise half journey [ $4 / 8$ or $1 / 2-$ ASCII (hex) $-00 \mathrm{BD}]$ of the Ascending Stairways for the East Zone [Lower Seashore] and sets in South.

The so-called Sun [Bullet] turns back from the setting point and rises from South and covers semi-clockwise half journey [3/4 - ASCII (hex) $-00 \mathrm{BE}$ for the Middle Stair and 1/4 - ASCII (hex) - 00BC for the Topmost Stair] of the Ascending Stairways for the West Zone [Upper Seashore] and ends in North.

North is the E-Point i.e. entering point and end point of Equal \& Opposite stages of journey of the Manifested Sign of Natural Magnetism [so-called Sun or Bullet or Electromagnetic Wave of Einstein]. South is the T-Point i.e. Turning Point of the Manifested Sign of Natural Magnetism [so-called Sun or Bullet or Electromagnetic Wave of Einstein]. So, the so-called Sun [Bullet] rises twice and sets twice from North to South \& South to North to cause the alteration of Day \& Night for the Equal \& Opposite East Zone and West Zone. There is no Common Run or Crookedness in the Manifested Nature in correspondence with Equal \& Opposite Revelation. Those who have the capability to argue against Irreversible Manifest Truths are invited to play Magical Game with 'Kitaaba Wal-Hikmata'.

Equal \& Opposite Manifested Sign of Natural Magnetism is the Standard [Criterion] of determining Revealed Left and Manifested Right i.e. North or Haiyalas-Swalaah as well as Revealed Right and Manifested Left i.e. South or Haiyalal-Falaah.

Due to acquired knowledge of invented lies and introduced falsehoods in the name of Scientific Certainties and Formal Education as well as uninterrupted propagation of the Nexus of Teleological Evidence Sorceries called Plagiarisms in the name of Research Project, mankind in general are far from true concepts of Manifested Nature, Four Cardinal Directions, and Irreversible Manifest Truths. Consequently, from the depth of darkness, the socalled \& self-sensed epistemic persons are trying to elevate animals as per with human by liberating them from Manifested Nature. While, animals like birds are aware of Natural Magnetic Directions. They move in the morning towards entering / rising direction of the appointed Light in search of the means of sustenance and return back in their nest in the evening in resemblance with the setting / ending direction of the appointed Light.

There are signs of Equal \& Opposite Moons [Uranus \& Neptune Muzzammil \& Muddassir] for the Equal \& Opposite West Zone and East Zone. New Moon or commonly perceived white moon is nothing but a sign such as smoke is the sign of the existence of fire The propagation of repeated visiting in Moons or smoke is the Trinity of Manifest Hypocrisy - Teleological Evidence Sorcery Extreme Epistemic Persecution.

There are three Axis, namely, Major Axis, Minor Axis, and SemiMajor Axis. Axis is a Triangular Path. Moreover, Axis represents Arithmetic Progression [Quarterly / Periodic Motion] of the Equal \& Opposite Moons for the Equal \& Opposite Upper Seashore and Lower Seashore. Elliptical ways are the two broadways [Safa and Marwa] for the Geometric Progression [Rapid Succession] of the socalled Sun [Bullet].

When the so-called Sun [Bullet / Sister Planet Venus] enters from North-East as the Morning Show for the East Zone, the so-called new Moon of the West Zone arises from the same root i.e. North-

\section{Volume 6 Issue 1, January 2017}




\section{International Journal of Science and Research (IJSR) ISSN (Online): 2319-7064 \\ Index Copernicus Value (2015): 78.96 | Impact Factor (2015): 6.391}

people of the Equal \& Opposite Zone i.e. Arabian Peninsula of the Upright West Region of the West Zone as well as North America and South America of the East Zone will observe Idd prior to Asia of the West Zone. People of India will observe Idd on the following Day. Consequently, people of India have failed to observe a single Idd on the Appointed Day.

Manifest Hypocrites are those who are inventing lies either contrary or contradictory to Manifest Truth. Teleological Evidence Sorcerers are those who are without Broken Bar introducing falsehoods in the name of Scientific Certainties within the Domain of Formal Education on the basis of Universal Concern, Unanimous Agreement, Global Rights, and Manmade Mandates. Extreme Epistemic Persecutors are those who are recognising and certifying researched falsehoods [Nexus of Self-evident Plagiarisms] as Manifest Truths without Verification and Justification of the researched findings on the basis of Revealed and Established Criterions of Truth in resemblance with Universal Major Premises [Coded Shared Tautologies].
West for the West Zone following Right Double Quotation Mark [ASCII (hex) - 0094] and follows Uniform Periodic Motion. So, the concept of Day origins from the East Zone and the concept of Night origins from the West Zone.

When the so-called Sun [Bullet / Sister Planet Venus] turns back from the setting point due to Broken Bar [ASCII (hex) - 00A6] and rises from South-West as the Evening Show from the point of view of Sister Planet Venus but Morning Show from the point of view of West Zone, the so-called new Moon of East Zone appears from South-East for the East Zone following Left Double Quotation Mark [ASCII (hex) - 0093] and follows Uniform Quarterly Motion. So, the concept of Day begins from West Zone and the concept of Night begins from East Zone.

Idd should be observed on the basis of arising of new Moon for the West Zone. So, people of Australia, Africa, Asia, Arabian Peninsula, and Europe will observe Idd on the same morning prior to people of the East Zone. People of North America and South America of the East Zone will observe Idd on the Equal \& Opposite Morning following West Zone.

i) Two Contraries [Black \& White] cannot be true together, though they both may be false together.

ii) Two Contradictories [Black \& Non-black] can neither be true together nor false together.

iii) Each Coded Shared Tautology like 'Man is mortal' is a Universal Major Premise of the Dictum De Omni Et Nullo, Cartesian Method, Deductive Method, and Cogito Ergo Sum i.e. Recognition \& Confirmation of a searched out Manifest Truth

There is no manmade Mandate or Law or Clause or Article or Chapter or Universal Concern or Unanimous Agreement or Global Rights or Human Rights or Environmental Law or the like which has Sovereignty [Dominion] over Manifested Nature. Manifested Nature is guided by the two pre-conditions [pre-suppositions] of knowledge or what Kant calls Apriori Principles or what Science calls Uniform Principle \& Uniform Motion i.e. Principle of the Uniformity of Nature and Equal \& Opposite Law [Equal \& Opposite Manifested Sign of sole Magnetism]. This Equal \& Opposite Law is called Trinity or Sirius Binary System. So, the Universe is a Sirius Binary System. Searched out Manifest Truths shared in the 'Kitaaba Wal-Hikmata' or 'Manifested Nature and the Utility of One's Upright Logic' of Jamir Ahmed Choudhury, Published by Partridge Publishing, 2016, are beyond Contrary Formalities and Contradictory Guidelines prevailing in the domain of Formal Education in the name of Mandates. Those who have self-evident concepts of the Trinity, Sirius Binary System, Universe, World, Earth, Four Basic Forces, Four Cardinal Directions, Six Manifested Directions, Three Ascending Stairways, Helium - 4, Two West \& Two East, West Horizon \& West Zone, East Horizon \& East Zone, Six Regions, Manifested North [E-Point / Haiyalas-Swalaah / Aphelion], Manifested South [T-Point / Haiyalal-Falaah / Perihelion], Equal \& Opposite Manifested Sign of Sole Magnetism from North to South \& South to North, Three Stages of Journey, Two Broadways \& Two Highways, Orbit \& Axis, Equal \& Opposite Moons for the Equal \& Opposite Seashore, Moon as Earth's Permanent Natural Satellite and Moon as Non-luminous East Horizon [Black Square], Uniform Periodic Motion of the Signs of Equal \& Opposite Moons, Right Direction of performing Salat [Namaz] towards Arsh [Upright West] facing each other, Appointed Day of observing Idd Uniformly etc. are requested to verify, justify, reject, confirm, recognise, generalise, broadcast, and the like of the searched out Manifest Truth shared for the First Time in the 'Kitaaba Wal-Hikmata' or 'Manifested Nature and the Utility of One's Upright Logic' published by Partridge Publishing India, 2016, for the sake of the 'Sanctity of Education', 'Utilitarian Liberation', and 'Survival of the Truest'.

Mandates - Two Contraries i.e. Both Set - A and Set - B cannot be true together, though they both may be false together.

Mandates - Two Contradictories i.e. Both Set - A and Set - B can neither be true together nor false together. In other words, the Truth of Set - A implies the Falsity of Set - B, and Conversely. That means, if Set - B represents Manifest Truth, then Set - A represents the package of the Trinity of Manifest Hypocrisy - Teleological Evidence Sorcery - Extreme Epistemic Persecution, Duality of Black \& White Activism and Mechanical Persecution, Vera Causa of leading mankind from the appointed light to the depth of darkness projecting veil of ignorance, causeless cause of leading Muslims towards wrong direction [Straight Middle-East Region of Bermuda Triangle / Black Hole / Penetrated Hole in the journey boat of Muussa (ass), Hollow in the Hand] in resemblance with the wrong dialling shown in the film PK [Pak Kalam / Pak Kalima / Pak Katha].

Newton's Equal \& Opposite Law and Copernican Revolution are contradictory to each other. One is verifiable Science and the other is the Historical Trinity of Manifest Hypocrisy, Teleological Evidence Sorcery, and Extreme Epistemic Persecution. Alteration of Day \& Night [Injiil] corresponds with Equal \& Opposite Law [Tawraat]. So, Copernican Revolution is a Scientific Persecution with respect to uninterrupted killing of Faith and Belief of Mankind on Scientific Certainty and Formal Education regardless of Class, Caste, Ism, Nation, Tribe etc. All pen-paper-pencil works and mechanisms in resemblance with Copernican Revolution are nothing but the propagation of the Nexus of Self-evident Plagiarisms.

Kepler's Elliptical Axis is the Experimentum Crusis and Crucial Instance regarding the Vera Causa of Self-contradictions and Paradoxes historically prevailing in the domain of Scientific Certainty and Formal Education. It is the product of Triangular Axis and Elliptical Orbits.

Manmade Magnetism is an invented lie and introduced falsehood in the name of Scientific Certainty and Formal Education in correspondence with the introduced Dead Calf of Firawn.

Owner, Possessors, Introducers, Interpreters, and Propagators of Copernican Universal Mal-observation, Kepler's Elliptical Axis, Solar System, Manmade Magnetism, Two False North \& Two False South, Running \& Moving Global Trinity and Quaternary, Post Hoc Ergo Propter Hoc Statistics, 6310 Critical Remarks [Commentaries] on Quran, Manmade Mandates [contrary formalities \& contradictory guidelines] with respect to Manifest Truth, Manifested Nature etc. are not only the Trinity of Manifest Hypocrites, Teleological Evidence Sorcerers, Extreme Epistemic Persecutors, but also International Scientific Soldiers [ISS] of Activism and Terrorism.

Sole purpose of Education is to acquire True Knowledge [Vidya or Real Light] for the Survival of the Truest. Sole duty of a teacher is to share verifiable truth of facts [Verifiable Science / Certain Knowledge] and justifiable necessary truth [Justifiable Philosophy / Valid

Volume 6 Issue 1, January 2017 www.ijsr.net

Licensed Under Creative Commons Attribution CC BY 


\section{International Journal of Science and Research (IJSR) \\ ISSN (Online): 2319-7064}

Index Copernicus Value (2015): 78.96 | Impact Factor (2015): 6.391

Knowledge] as a Duty for Duty's Sake as well as Greatest Happiness of the Greatest Number. Sole desire of a re-search scholar is to search out Manifest Truth on the basis of observation of particular instances and criterions of truth in resemblance with at least one universal major premise. Sole responsibility of a human person is to recognise and confirm Manifest Truth and to remove doubt regarding Principle of the Uniformity of Nature and Equal \& Opposite Manifested Sign of Natural Magnetism from North to South \& South to North. Sceptic of Manifest Truth [Injiil in correspondence with Tawraat] such as David Hume is instructed to commit suicide with a view to get pragmatic certificate of a necessary relation between Equal \& Opposite Birth \& Death.

\section{References}

'Kitaaba Wal-Hikmata' or 'Manifested Nature and the Utility of One's Upright Logic' Vol. - 1, Published by Partridge Publishing India, on $5^{\text {th }}$ August, 2016

Sharer - Jamir Ahmed Choudhury, Pages - 740, Language - English

ISBN (13) - 9781482875034 / 9781482875027 / ISBN (10) - 1482875039 / 1482875027

ASIN - B01LFG1B82 / OCLC - 956692563 / EAN - 9781482875034

Kitaaba Wal-Hikmata' or 'Manifested Nature and the Utility of One's Upright Logic' Vol. - 2, Published by Partridge Publishing India, on $9^{\text {th }}$ December, 2016

Sharer - Jamir Ahmed Choudhury, Pages - 840, Language - English

ISBN (13) - $9781482875003 / 9781482875010$

ISBN $(10)-1482875004$

All Verifiable Scientific Laws and Justifiable Philosophical Theories

Uncountable Pen-Paper-Pencil Works and Mechanical Activities Prevailing in the History of Epistemology, Publication Media, and Broadcasting Media as the Nexus of Self-evident Plagiarisms

If it is decided on the basis of Universal Concern, Unanimous Agreement, Global Rights, International Harmony, Common Run, Rotation \& Revolution System, Manmade Magnetism, Kepler's Elliptical Axis, Napier Bones, Manmade Mandates with respect to Manifest Truth \& Manifested Nature, and the like that the sole purpose of Formal Education is to acquire \& share invented lies and introduced falsehoods of the members of ISS of Activism \& Terrorism either contrary to Manifested Nature or contradictory to Irreversible Manifest Truth, then I have to expect nothing from Honourable Chairs, Respective Authorities, Public Representatives, Govt. Officials, Epistemic Persons, Possessors of Balanced Good Sense, and Mankind in general save to resign from the Govt. appointed duty and to surrender PhD Registration [Ref. Ph. D D/2491/14 Dated 21/03/2014 under AUS] before the table of the Honourable Chancellor, Assam University, Silchar [AUS], through the Office of the Vice-Chancellor, AUS, India.

\section{Erase Falsehoods and Share Irreversible Manifest Truths}

Each human person has the Solidarity Rights [Third Generation Human Rights] to acquire / share true knowledge with a view to recognise and confirm individual faith \& belief on Manifest Truth [Manifested Nature / First Generation Human Rights]. Honourable Chairs, Respective Authorities, and Possessors of True Knowledge are honestly \& sincerely requested to verify \& justify searched out Manifest Truths shared in the 'Kitaaba Wal-Hikmata' of Jamir Ahmed Choudhury on the basis of observation of particular instances \& four revealed \& established criterions of Truth as well as in resemblance with at least one Universal Major Premise [Coded Shared Tautology] following Logical Methods [Dictum De Omni Et Nullo, Cartesian Method, and Deductive Method], to make an attempt with a view to erase invented lies \& introduced falsehoods from the domain of the prevailing history of Epistemology, to take preventive measure with a view to put the Broken Bar in the propagation of the Nexus of Selfevident Plagiarisms prevailing in the ongoing pen-paperpencil works \& mechanisms as well as publication media \& broadcasting media, to amend prevailing contrary formalities \& contradictory guidelines as well as illicit reference list with respect to verification \& justification and recognition \& confirmation of the searched out Manifest Truth, to apply reformative mandates with a view to share Manifest Truths openly \& publicly, to provide retributive punishment to the Trinity of Manifest Hypocrites - Selfevident Evidence Sorcerers - Extreme Epistemic Persecutors as well as each member of the ISS of Activism \& Terrorism.

In this regard, Twenty Five Class - II standard fill in the blanks are being placed with alternative options. With a view to erase falsehoods from the domain of Formal Education and to introduce Manifest Truths within the Sphere of Formal Education (True Knowledge), we are to recognise and confirm verifiable as well as justifiable alternative option. So, possessors of true knowledge are sincerely requested to share true alternative option in correspondence with Manifested Nature [Injiil] and in resemblance with Revealed Law [Tawraat] for the sake of nothing but Sanctity of Formal Education, Utilitarian Liberation, and Survival of the truest. This sharing will be the pragmatic instance as well as self-evident evidence regarding the Quality of Knowledge searched out and shared for the First Time in the 'Kitaaba Wal-Hikmata' of Jamir Ahmed Choudhury, 2016. Moreover, it will also reflect the solid purpose of acquiring / sharing True Knowledge [Vidya / Light / Formal Education] as Duty for Duty's Sake [Nishkama Karma]

Further, Honourable Chairs and Respective Authorities are requested consciously to provide the Trinity of PreventiveReformative-Retributive Punishments to the sharer of 'Kitaaba Wal-Hikmata' or 'Manifested Nature and the Utility of One's Upright Logic', published by Partridge Publishing India, 2016, if illicit \& illegitimate sharing is found either in the placement of 'Justifiable Appeal' or in the 'Self-Published Searched out Manifest Truths shared as Solidified Solid Human Rights' for Verification, Justification, Recognition, Confirmation, and Public Broadcasting. 


\section{International Journal of Science and Research (IJSR) \\ ISSN (Online): 2319-7064}

Index Copernicus Value (2015): 78.96 | Impact Factor (2015): 6.391

\section{KAUN BANEGA JNANAPATI?}

\section{Self-evaluation}

Let us Test our possessed Epistemology selecting True Alternatives

1. Universe is a ------------ [Solar System / Sirius Binary System].

2. Universe is a --------------- [Planetary System / Star System].

3. Universe is like a --------------- [Globe / Diamond]

4. Manifested Universe resembles with a -----------[Running \& Moving Globe / Fixed Upright Rectangle]

5. Manifested World is a ---------------- [Running \& Moving Globe / Immovable Hexagon or Asterisk].

6. Earth is like the ---------------- [Projected Moving Globe / Pentagon or Star Operator or Spiders' Net in correspondence with appearing manmade 9/11 Pentagon].

7. Appearing Earth has ----------------- [no ascending or descending stairways / three ascending stairways].

8. There is only one Manifested Nature and [two kinds of Magnetism - Natural \& Manmade / only one kind of Magnetism or sole Natural Magnetism].

9. Manifested Magnetic Directions must be determined on the basis of --------- [Projected Manmade Magnetism / Manifested Equal \& Opposite stages of journey of the so-called Sun or Bullet or Einstein's Electromagnetic Wave or Binary Pulsar or Niche or Sister Planet Venus as the Sign of Sole Natural Magnetism from North to South \& turning back from South to North].

10. East represents ----------- [Magnetic Field Gravitational Field or Downward Direction].

11. West represents -------- [Weak Field / Strong Field or Upward Direction].

12. North represents ---------- [Strong Field / Magnetic Field or E-Point or Haiyalas-Swalaah].

13. South represents -------- [Gravitational Field / Weak Field or T-Point or Haiyalal-Falaah].

14. Newton's apple falls from the tallest tree towards ------------- [Weak Field or South / Gravitational Field or East or Downward Direction].

15. Rain comes from ------- [Magnetic Field or North / Strong Field or West or Sky].

16. The so-called Sun or Bullet or Einstein's Electromagnetic Wave or Sister Planet Venus enters within the Non-luminous Moon [Black Square] of East Horizon as Morning Show [Appointed Light as means of Sustenance] for the Ground Stair of North America and South America of the Lower Seashore [East Zone] from ------- [East or Gravitational Field / North or Magnetic Field] and sets in

[West or Strong Field / South or Weak Field] covering Semi-anticlockwise stages of journey [1/2].

17. The so-called [setting] Sun or Bullet or Einstein's Electromagnetic Wave or Sister Planet Venus turns back [due to Broken Bar] from the setting point [TPoint] and rises again within the Black Square [Nonluminous Moon] of East Horizon as Evening Show [Appointed Light as means of Sustenance] for the Middle Stair of Europe, Asia, Africa, and Australia as well as Topmost Stair of Arabian Peninsula of the Upper Seashore [West Zone] from ------------- [East or
Gravitational Field / South or Weak Field or T-Point] and ends in -------- [West or Strong Field / North or Magnetic Field or Entering \& Ending Point or E-Point] covering Semi-clockwise stages of journey [1/4+3/4].

18. Commonly perceived new Moon [white] of the West Zone [Upper Seashore of Australia, Africa, Asia, Arabian Peninsula, and Europe i.e. Five Continents] as the Sign of Successive Relation arises from

[West or Strong Field / North or Magnetic Field or Single Root or E-Point] and follows $1^{\text {st }} \& 3^{\text {rd }}$ Quarters from --------- [West to East / North to South or Revealed left to right] and $2^{\text {nd }} \& 4^{\text {th }}$ Quarters from --------- [East to West / South to North or Manifested left to right] uniformly.

19. Commonly perceived new Moon [white] of the East Zone [Lower Seashore of South America and North America i.e. two Continents] as the Sign of Successive Relation appears from [West or Strong Field / South or Weak Field or T-Point] and follows $1^{\text {st }} \& 3^{\text {rd }}$ Quarters from ----- [West to East / South to North or Revealed right to left] and $2^{\text {nd }} \& 4^{\text {th }}$ Quarters from ---- [East to West / North to South or Manifested right to left] uniformly.

20. Muslims of ----------------- [East Zone \& Upright West Region / Five Continents of the West Zone] will observe Idd prior to Muslims of ------------------[West Zone / Two Continents of the East Zone].

21. Penetrated-Hole in the journey boat of Muussa (ass] called Black Hole or Eartha 3D or Hollow in the Hand or Projected Planet Mars or Peg of the Immovable Hexagonal World \& Appearing Pentagonal Earth or Bermuda Triangle of Titanic represents [Manifested Upright West Region of Arabian Peninsula / Projected Straight Middle-East Region of Arabian Peninsula].

22. The manifested Black \& White Imam of the City called Kaba has been appointed on the ----------- [Projected Straight Middle-East Region of Arabian Peninsula / Right side of the Mount Tuur in the Manifested Upright West Region of Arabian Peninsula].

23. Manmade Magnetism is a / an ------------ [Scientific Certainty / Invented Lie \& Introduced Falsehood in correspondence with introduced Idol or God or Reality of Firawn].

24. Copernican Hypothesis is a / an ------------ [Scientific Certainty / Invented Lie \& Introduced Falsehood in resemblance with Dog's Paw of ISS of Activism \& Terrorism].

25. Kepler's Elliptical Axis is a / an --------- [Scientific Certainty as well as a Tautology / Invented Lie \& Introduced Falsehood as well as the seed of Selfcontradiction \& Paradox].

\begin{abstract}
Note:- 'Kitaaba Wal-Hikmata' or 'Manifested Nature and the Utility of One's Upright Logic' of Jamir Ahmed Choudhury, Published by Partridge Publishing India, 2016, is the First Pen-Paper-Pencil Work in the History of Epistemology which not only explores Manifest Hypocrisy, Teleological Evidence Sorcery, Extreme Epistemic Persecution, Propagation of Self-evident Plagiarisms etc. but also shares Manifest Truth [Injiil] in correspondence with Equal \& Opposite Revelation [Tawraat] i.e. verifiable and justifiable Epistemology.
\end{abstract}

\section{Volume 6 Issue 1, January 2017




\section{International Journal of Science and Research (IJSR) \\ ISSN (Online): 2319-7064}

Index Copernicus Value (2015): 78.96 | Impact Factor (2015): 6.391

Each searched out finding is related with Scientific Certainties, Infallible \& Unerring Mandates, Formal Education, and Faith \& Belief of Human Persons living in Societies i.e. Social Justice. But with reference to Letter No. 17016/51/2016-SCO-VI Dated $27^{\text {th }}$ October, 2016, Received from the Department of Social Justice and Empowerment Ministry, Govt. of India, the 'Justifiable Appeal' placed before the tables of some Honourable Chairs and Respective Authorities on $\mathbf{2 6}^{\text {th }}$ September, 2016 'does not come under the Mandates of Social Justice and Empowerment Ministry', Govt. of India. So, the question is - 'Which one of the above shared Manifest Truths is not related with human persons living in societies i.e. Social Justice / Solidarity Rights? On the contrary, with reference to Letter No. 19016/03/2016 Dated $2^{\text {nd }}$ December, 2016, and referred Clause 5(b) of the Article 338 of the Constitution of India, the Department of Social Justice and Empowerment Ministry, Govt. of India, has related 'Justifiable Appeal' for recognition and confirmation of the above shared Irreversible Manifest Truths with Scheduled Caste, and correspondingly referred the 'Justifiable Appeal' to the Respective Joint Secretary, National Commission for Scheduled Caste. So, the question is - 'Which of one the above shared Irreversible Manifest Truths is related with Scheduled Caste and Clause 5(b) of the Article 338 of the Constitution of India'?

Now, following the suggestions [Ref. Letter No. $17016 / 51 / 2016-$ SCO-VI Dated $27^{\text {th }}$ October, 2016, Received from the Department of Social Justice and Empowerment Ministry, Govt. of India], once again 'Justifiable Appeal' regarding [necessary arrangement for] verification, justification, rejection, confirmation, general recognition, and public broadcasting of the searched out Manifest Truths shared in the 'Kitaaba Wal-Hikmata' or 'Manifested Nature and the Utility of One's Upright Logic' Vol. - 1 \& 2 of Jamir Ahmed Choudhury, published by Partridge Publishing India, 2016, is being placed before the Tables of Honourable Chairs, Respective Authorities, Respective Educational Organisations, Respective Commissions, Respective Educational Councils, Respective Research Institutions, Respective Govt. Officials as well as Honourable Public Representatives, Epistemic Persons, Possessors of Balanced Good Sense, Media Persons, and Mankind in general regardless of Class, Caste, Ism, Nation, Tribe, Gender etc. as Duty for Duty's Sake [Nishkama Karma] for the sake of the Sanctity of Education, Utilitarian Liberation, Survival of the Truest, Solidified Solid Human Rights, and the like. It is expected that each authority will reflect on the searched out Manifest Truths and Manifested Nature with a view to do Justness with 'Justifiable Appeal' of a human person living in society in the Manifested Hexagonal World appearing as a Pentagonal Earth with three ascending stairs within the Non-luminous Moon [Black Square] of East Horizon [Saturn].

Expecting upright justness with Manifested Nature, searched out Manifest Truths, Formal Education, Teaching Profession, Re-search Work, Solidified Solid Human Rights, and Individual Faith \& Belief on what are being taught as two Pre-suppositions of True Knowledge i.e. Principle of the Uniformity of Nature as well as Equal \& Opposite Law i.e. Equal \& Opposite stages of journey of the Manifest Sign of Sole Magnetism [Bullet] from North to South for the two continents of the East Zone and South to North for the five continents of the West Zone.

\section{Author Profile}

Jamir Ahmed Choudhury is Asst. Prof. Dept. of Philosophy, S S. College, Hailakandi, Assam, Re-search Scholar on 'Solidarity Rights in Islam', Under Assam University, Silchar, [AUS]. Registration No. - Ph. D/2491/14 Dated 21/03/2014 